\title{
Reasons for Aripiprazole Discontinuation in Schizophrenia - A Retrospective Review
}

\author{
Aurelie Millier $^{1^{*}}$, Benjamin Briquet ${ }^{1}$, Nadia Georges $^{2}$, Venkatesha Murthy ${ }^{3}$ and Mondher Toumi ${ }^{4}$ \\ ${ }^{1}$ Creativ-Ceutical, 215 rue du Faubourg Saint Honoré 75008 Paris, France \\ ${ }^{2}$ Takeda Pharmaceuticals International Gmbh Thurgauerstrasse 130, Zurich, Switzerland \\ ${ }^{3}$ Medical Director, Clinical Neuroscience, Takeda Pharmaceuticals International, Inc, United Kingdom \\ ${ }^{4}$ University Claude Bernard Lyon I, UFR d'Odontologie 11, France
}

*Corresponding author: Aurelie Millier, Creativ-Ceutical 215 rue du Faubourg Saint Honoré, 75008 Paris France, Tel: (+33)176704797; E-mail: ami@creativceutical.com

Received date: June 16, 2014, Accepted date: Sep 06, 2014, Published date: Sep 15, 2014

Copyright: (C) 2014 Millier A, et al. This is an open-access article distributed under the terms of the Creative Commons Attribution License, which permits unrestricted use, distribution, and reproduction in any medium, provided the original author and source are credited.

\begin{abstract}
Objectives: Patients with schizophrenia taking first- or second-generation antipsychotic drugs may switch to treatment with Aripiprazole due to side effects. This atypical antipsychotic launched in Europe in 2004, and has a better reported safety profile. However, patients also discontinue Aripiprazole, despite the lack of a comparable alternative antipsychotic. As very few data are available in the literature, it seems important to investigate the reasons for Aripiprazole discontinuation.
\end{abstract}

Methods: A retrospective multicenter observational study of 287 patients with schizophrenia was conducted in France, Germany and Sweden. Eligible patients were treated with aripiprazole in the last two years and were switched to another antipsychotic. Their psychiatrists were asked to report online the reasons for discontinuation of aripiprazole and of previous antipsychotic treatments.

Results: Considering the whole sample, reasons for aripiprazole discontinuation were poor efficacy with respect to positive (44\%) and negative (31\%) symptoms and intolerable side effects $(27 \%)$. No significant difference was found between antipsychotic-naïve patients and the rest. These reasons were given for $40 \%, 25 \%$ and $52 \%$ of patients, respectively, for discontinuation of previous antipsychotic treatments.

Conclusion: Aripiprazole seems to be prescribed mainly after intolerable side effects are observed with other therapies. Aripiprazole was discontinued due to lack of efficacy for positive and negative symptoms at rates greater than those for intolerable side effects.

Keywords: Schizophrenia; Aripiprazole; Discontinuation; Antipsychotics; Survey; Safety; Efficacy

\section{Introduction}

Schizophrenia is a chronic and disabling psychiatric disorder affecting approximately $1 \%$ of the population world-wide [1]. Symptoms are frequently categorized as positive, negative and cognitive [2]. The degree of suffering and disability in schizophrenia is considerable, with $80-90 \%$ not working [3] and an overall mortality rate twice to three times as high as in the general population [4]. Pharmacological treatment of schizophrenia consists mainly of antipsychotic drugs. None of these are completely satisfactory, and the pharmaceutical industry continually seeks improved alternatives.

Typical antipsychotic drugs (also called first-generation antipsychotics (FGA) have traditionally been used as first-line agents for people with schizophrenia [5]. FGAs are known to cause many kinds of side effects, including mainly extrapyramidal symptoms (EPS). Second-generation antipsychotic (SGA) have proven to be at least comparable in efficacy to FGAs, and have a more favorable overall side effect profile, though many of them have metabolic issues or cardiac side effects [6]. Weight gain is one of the major drawbacks associated with the SGAs: compared to patients on FGAs, these patients have higher rates of morbidity and mortality, largely due to weight gain and metabolic syndrome [7].

Switching to an antipsychotic with a lower propensity to induce weight gain is an attractive strategy, and aripiprazole seems a candidate for such a treatment strategy. Aripiprazole was approved by the US Food \& Drug Administration (FDA) in 2002 for treatment of schizophrenia.

It has shown acceptable efficacy, and good safety: adverse effects include akathisia, somnolence, headache, gastrointestinal upset and light headedness [8]. The recommended target dose for aripiprazole is 10-15 $\mathrm{mg}$ per day (dose range 10-30 $\mathrm{mg} /$ day) [9].

In 2006, El-Sayeh et al. [10] published a systematic review suggesting that aripiprazole did not differ significantly from some typical or other atypical antipsychotics in terms of several global outcomes and adverse effects. Nevertheless the authors acknowledged the lack of available evidence, and the limited numbers of comparator drugs used in the included trials. In 2012, a review of use of aripiprazole in the management of schizophrenia in adults was published [11]. It reported that improvements in remission rates and response rates favoured aripiprazole over haloperidol, but that 
improvements in positive and negative symptom scores mostly favoured olanzapine over aripiprazole. Longer-term treatment generally favoured patients switched to receive aripiprazole compared with standard-of-care oral antipsychotics. Aripiprazole was generally well tolerated in patients with schizophrenia, and aripiprazole was associated with a favourable cardiovascular tolerability profile compared to olanzapine. Later in 2013, Leucht et al. [12] published a multiple-treatments meta-analysis comparing 15 antipsychotics. Aripiprazole showed similar efficacy than most of antipsychotics (except clozapine, amisulpride and olanzapine, reporting a significantly higher efficacy), and a good safety profile. Finally, in 2013, 12 trials comparing aripiprazole to olanzapine, risperidone or ziprasidone were reviewed. Considering global state, no difference in efficacy was found between the products, but olanzapine was better with regards to mental state. Regarding safety, no significant difference in EPS was shown, but aripiprazole was found less likely than comparators to increase cholesterol levels or cause weight gain and it is an antipsychotic with a variant but not absent adverse effect profile.

Patients, who switch to aripiprazole to mitigate weight gain and metabolic problems associated with other antipsychotics, may switch therapy again. Little has been described regarding discontinuation of aripiprazole treatment and it seemed important to better understand why patients discontinue treatment with aripiprazole in real life.

\section{Methods}

\section{Data collection}

The objective of this study is to determine why patients with schizophrenia stopped treatment with aripiprazole; their reasons were assessed by their psychiatrists. To that purpose, we conducted an online survey in Sweden, Germany and France.

We contacted psychiatrists having more than 5 years of experience treating patients with schizophrenia, and more than 5 patients with schizophrenia currently followedup. The study source population included patients with schizophrenia treated by the participating psychiatrists, who met the inclusion criteria and none of the exclusion criteria, as per the following:

Age 18-75 years

Diagnosis of schizophrenia as assessed by DSM-IV for at least 2 years (paranoid, undifferentiated, catatonic, residual or disorganized type)

Outpatient treatment by a psychiatrist

Treatment with aripiprazole during the last 12 months, and switch to another antipsychotic (no more than 2 weeks without treatment between aripiprazole and the other antipsychotic)

Exclusion criteria included:

Treatment with aripiprazole during the last 2 years in combination with another antipsychotic for more than $25 \%$ of the duration of aripiprazole therapy

Any active substance abuse disorder (except alcohol, nicotine and caffeine) within the previous 6 months

Chronic hospitalization during the whole previous year

Not being continuously followed by the participating psychiatrist since initiation of aripiprazole
Data were collected retrospectively by psychiatrists from electronic records at each participating psychiatrist's practice location. Each psychiatrist retrieved patients with schizophrenia meeting inclusion and exclusion criteria in consecutive, reverse chronological order to avoid selection bias, starting with the patient who most recently switched from aripiprazole to any other antipsychotic. Psychiatrists were limited to inclusion of 4 patients, to ensure results are not driven by a low number of psychiatrists.

All data were recorded in anonymous-coded electronic forms. Patients were identified on the data collection form only by a unique number linked to the site number. Patient informed consent was not sought for this study since anonymised patient data do not fall within the scope of data protection laws. These data are no attributable to any individual patient, and the patient is neither identifiable nor definable.

Once the first 10 psychiatrists were enrolled, data were verified to identify any issues related to quality, accuracy or consistency of data collection requiring clarification or further explanation before data collection continued.

The study sample has not been based on a statistical calculation but has been chosen pragmatically, as the study is descriptive and does not involve any intervention on patients. A sample size of 300 patients (100 in each country) was considered appropriate for this study.

Collected data included prescriber demographic characteristics, demographics and other patient characteristics, disease history, antipsychotic treatment and concomitant medication.

Reasons for discontinuation included in the survey were poor efficacy with respect to positive symptoms (worsening of symptoms or lack of improvement), poor efficacy with respect to negative symptoms (idem), lack of access or financial reasons, intolerable side effects, comorbid mental condition, co-morbid physical condition, cardiovascular or metabolic event, or other reason. Several answers were allowed.

\section{Statistical analysis}

Statistical analyses are mainly descriptive. Quantitative variables are summarized using usual descriptive statistics, including number of missing values, number of valid values, and their observed mean and standard deviation. Qualitative variables are summarized presenting numbers of missing and valid values, and frequency and percentage of each level of the variable. Reasons for discontinuation were described separately for antipsychotics-naïve patients (receiving aripiprazole as a first-line antipsychotic), and patients having received other treatment(s) previously. Relevant test (Chi-Square or Student tests) were undertaken to compare different populations.

\section{Results}

\section{Prescriber and patient demographic characteristics}

In the 3 countries, recruitment started in November 2012. Recruitment ended in December 2012 in France and Germany and in January 2013 in Sweden. Ninety-five psychiatrists were recruited for this project: 37 in France, 39 in Germany and 19 in Sweden. Together they reported information for 287 patients (123 in France, 121 in Germany and 43 in Sweden). The average number of patients was 3.0 overall, 3.3 in France, 3.1 in Germany and 2.3 in Sweden. 
Citation: $\quad$ Millier A, Briquet B, Georges N, Murthy V, Toumi M (2014) Reasons for Aripiprazole Discontinuation in Schizophrenia - A Retrospective

Page 3 of 8

Table 1 presents prescriber and patient demographic characteristics. overall), in public (France) or in specialty clinics (Germany and Psychiatrists were mainly practicing in urban environments (79\% Sweden), with on average 16 years of experience.

\begin{tabular}{|c|c|c|c|c|c|c|}
\hline & & FRANCE & GERMANY & SWEDEN & ALL & PVALUE \\
\hline Psychiatrists & & $\mathrm{N}=37$ & $N=39$ & $\mathrm{~N}=19$ & $\mathrm{~N}=95$ & \\
\hline \multirow[t]{3}{*}{ Practice Environment } & Rural & $1(2.70 \%)$ & $4(10.26 \%)$ & 0 & $5(5.26 \%)$ & \multirow[t]{3}{*}{$p=0.16$} \\
\hline & Semi-urban & $9(24.32 \%)$ & $4(10.26 \%)$ & $2(10.53 \%)$ & $15(15.79 \%)$ & \\
\hline & Urban & $27(72.97 \%)$ & $31(79.49 \%)$ & $17(89.47 \%)$ & $75(78.95 \%)$ & \\
\hline \multirow[t]{6}{*}{ Practice type } & Private & $7(18.92 \%)$ & $3(7.69 \%)$ & 0 & $10(10.53 \%)$ & \multirow[t]{6}{*}{$p<0.0001$} \\
\hline & Academia & $1(2.70 \%)$ & $7(17.95 \%)$ & 0 & $8(8.42 \%)$ & \\
\hline & Specialty clinic & $1(2.70 \%)$ & $17(43.59 \%)$ & $13(68.42 \%)$ & $31(32.63 \%)$ & \\
\hline & Public & $25(67.57 \%)$ & $3(7.69 \%)$ & $3(15.79 \%)$ & $31(32.63 \%)$ & \\
\hline & Combined private/public & $3(8.11 \%)$ & $7(17.95 \%)$ & $3(15.79 \%)$ & $13(13.68 \%)$ & \\
\hline & Other & 0 & $2(5.13 \%)$ & 0 & $2(2.11 \%)$ & \\
\hline $\begin{array}{l}\text { Number of years since } \\
\text { thesis }\end{array}$ & Mean (SD) & $16.81(6.36)$ & $17.44(9.65)$ & $11.84(5.73)$ & $16.07(8.00)$ & $p=0.03$ \\
\hline Patients & & $\mathrm{N}=123$ & $N=121$ & $\mathrm{~N}=43$ & $N=287$ & \\
\hline \multirow[t]{2}{*}{ Gender } & Male & $75(60.98 \%)$ & $78(64.46 \%)$ & $30(69.77 \%)$ & $183(63.76 \%)$ & \multirow[t]{2}{*}{$p=0.57$} \\
\hline & Female & $48(39.02 \%)$ & $43(35.54 \%)$ & $13(30.23 \%)$ & $104(36.24 \%)$ & \\
\hline Age & Mean (SD) & $32.90(11.08)$ & $34.15(11.52)$ & $35.79(8.52)$ & $33.86(10.94)$ & $p=0.31$ \\
\hline \multirow[t]{2}{*}{ Family situation } & Single & $97(77.60 \%)$ & $73(81.11 \%)$ & $59(75.64 \%)$ & $219(76.31 \%)$ & \multirow[t]{2}{*}{$p=0.27$} \\
\hline & Couple & $28(22.40 \%)$ & $17(18.89 \%)$ & $19(24.36 \%)$ & $68(23.69 \%)$ & \\
\hline \multirow[t]{3}{*}{ Living conditions } & Alone & $52(41.60 \%)$ & $44(48.89 \%)$ & $36(46.15 \%)$ & $117(40.77 \%)$ & \multirow[t]{3}{*}{$p=0.002$} \\
\hline & Family & $59(47.20 \%)$ & $39(43.33 \%)$ & $37(47.44 \%)$ & $142(49.48 \%)$ & \\
\hline & Other & $14(11.20 \%)$ & $7(7.78 \%)$ & $5(6.41 \%)$ & $28(9.76 \%)$ & \\
\hline \multirow[t]{2}{*}{ Number of children } & No children & $98(79.67 \%)$ & $67(79.76 \%)$ & $58(76.32 \%)$ & $220(79.42 \%)$ & \multirow[t]{2}{*}{$p=0.45$} \\
\hline & 1 or more children & $25(20.33 \%)$ & $17(20.24 \%)$ & $18(23.68 \%)$ & $57(20.58 \%)$ & \\
\hline \multirow{3}{*}{$\begin{array}{l}\text { Employment } \\
\text { occupational status }\end{array}$} & Paid & $18(14.40 \%)$ & $11(12.22 \%)$ & $12(15.38 \%)$ & $44(15.33 \%)$ & \multirow[t]{3}{*}{$p=0.002$} \\
\hline & Voluntary/Sheltered employment & $18(14.40 \%)$ & $16(17.78 \%)$ & $17(21.79 \%)$ & $45(15.68 \%)$ & \\
\hline & Unemployed/Other & $89(71.20 \%)$ & $63(70.00 \%)$ & 49 (62.82\%) & 198 (68.99\%) & \\
\hline \multirow{4}{*}{$\begin{array}{l}\text { Highest completed level } \\
\text { of education }\end{array}$} & Primary & $39(31.20 \%)$ & $26(28.89 \%)$ & $24(30.77 \%)$ & $87(30.31 \%)$ & \multirow[t]{4}{*}{$p<0.0001$} \\
\hline & Secondary & $52(41.60 \%)$ & $39(43.33 \%)$ & $41(52.56 \%)$ & $129(44.95 \%)$ & \\
\hline & Tertiary & $20(16.00 \%)$ & $18(20.00 \%)$ & $12(15.38 \%)$ & $46(16.03 \%)$ & \\
\hline & Other & $14(11.20 \%)$ & $7(7.78 \%)$ & $1(1.28 \%)$ & $25(8.71 \%)$ & \\
\hline \multirow[t]{5}{*}{ Schizophrenia type } & Paranoid & $91(72.80 \%)$ & $54(60.00 \%)$ & $50(64.10 \%)$ & $189(65.85 \%)$ & \multirow[t]{5}{*}{$p=0.0002$} \\
\hline & Catatonic & $3(2.40 \%)$ & $4(4.44 \%)$ & $5(6.41 \%)$ & $13(4.53 \%)$ & \\
\hline & Disorganized & $15(12.00 \%)$ & $13(14.44 \%)$ & $8(10.26 \%)$ & $32(11.15 \%)$ & \\
\hline & Undifferentiated & $11(8.80 \%)$ & $10(11.11 \%)$ & $13(16.67 \%)$ & $38(13.24 \%)$ & \\
\hline & Residual & $5(4.00 \%)$ & $9(10.00 \%)$ & $2(2.56 \%)$ & $15(5.23 \%)$ & \\
\hline
\end{tabular}


Citation: $\quad$ Millier A, Briquet B, Georges N, Murthy V, Toumi M (2014) Reasons for Aripiprazole Discontinuation in Schizophrenia - A Retrospective Review. J Neurol Neurophysiol 5: 226. doi:10.4172/2155-9562.1000226

Page 4 of 8

\begin{tabular}{|l|l|l|l|l|l|l|}
\hline $\begin{array}{l}\text { Number of years since } \\
\text { schizophrenia diagnosis }\end{array}$ & Mean (SD) & $9.81(8.25)$ & $10.59(9.56)$ & $9.81(7.89)$ & $9.57(8.36)$ & $p=0.55$ \\
\hline $\begin{array}{l}\text { Any concomitant mental } \\
\text { conditions }\end{array}$ & No & $106(84.80 \%)$ & $76(84.44 \%)$ & $60(76.92 \%)$ & $243(84.67 \%)$ & $p=0.51$ \\
\cline { 2 - 7 } & Yes & $19(15.20 \%)$ & $14(15.56 \%)$ & $18(23.08 \%)$ & $44(15.33 \%)$ & $p=0.41$ \\
\hline $\begin{array}{l}\text { Any concomitant physical } \\
\text { conditions }\end{array}$ & No & $106(84.80 \%)$ & $80(88.89 \%)$ & $70(89.74 \%)$ & $255(88.85 \%)$ & \\
\cline { 2 - 7 } & Yes & $19(15.20 \%)$ & $10(11.11 \%)$ & $8(10.26 \%)$ & $32(11.15 \%)$ & \\
\hline
\end{tabular}

Table 1: Prescriber and patient demographic characteristics

Patients were predominantly male (64\%), and average age was 34 years. They were generally single (76\%), lived alone or with their family (respectively $41 \%$ and $49 \%$ of all patients), had no children (79\%), were unemployed (69\%), and had completed at best their primary or secondary education (75\%). These demographic results were generally similar across countries.

Paranoid schizophrenia was the most frequent diagnosis among the five schizophrenia diagnoses (66\%), followed by undifferentiated $(13 \%)$ and disorganized schizophrenia (11\%). The schizophrenia diagnosis of patients was made on average 9.57 years before their psychiatrist responded to the survey. Some $15 \%$ of the patients were suffering concomitant mental conditions, such as depression, insomnia, anxiety and alcohol abuse, and $11 \%$ suffered from concomitant physical conditions (for example diabetes or cardiovascular events were reported for $6 \%$ of patients).

\section{Antipsychotic treatment}

Table 2 presents antipsychotic treatment taken before aripiprazole and during aripiprazole treatment. Of the 287 patients included in the study, 89 (31\%) were prescribed aripiprazole as their first antipsychotic treatmentand 198 (69\%) were using other antipsychotic treatments before aripiprazole. Before using aripiprazole, $93 \%$ of these patients were treated with monotherapy (only one antipsychotic treatment prescribed at a time), and $7 \%$ with combination therapy (more than one antipsychotic treatment at a time). Before aripiprazole, mainly SGAs were prescribed (76\% of patients received oneSGA, and $17 \%$ received one FGA). The antipsychotics most prescribed prior toaripiprazole were risperidone (33\%), olanzapine (28\%), haloperidol $(10 \%)$ and quetiapine (10\%). The frequency of use of the various antipsychotic treatments varied from one country to another.

\begin{tabular}{|c|c|c|c|c|}
\hline & & $\begin{array}{l}\text { BEFORE ARIPIPRAZOLE } \\
(\mathrm{N}=198)\end{array}$ & $\begin{array}{l}\text { DURING ARIPIPRAZOLE } \\
(\mathrm{N}=199)\end{array}$ & PVALUE \\
\hline \multirow[t]{2}{*}{ Type of therapy } & Monotherapy & $185(93.43 \%)$ & $185(92.96 \%)$ & \multirow[t]{2}{*}{$p=0.85$} \\
\hline & Combination therapy & $13(6.57 \%)$ & $14(7.04 \%)$ & \\
\hline \multirow[t]{7}{*}{ Type of AP treatment } & FGA & $33(16.67 \%)$ & $5(35.71 \%)$ & \multirow[t]{7}{*}{ NA } \\
\hline & FGA-FGA & $4(2.02 \%)$ & 0 & \\
\hline & SGA & $151(76.26 \%)$ & $9(64.29 \%)$ & \\
\hline & FGA-SGA & $6(3.03 \%)$ & 0 & \\
\hline & FGA-FGA-SGA & $1(0.51 \%)$ & 0 & \\
\hline & SGA-SGA & $2(1.01 \%)$ & 0 & \\
\hline & SGA-SGA-SGA & $1(0.51 \%)$ & 0 & \\
\hline Duration of treatment (days) & Mean (SD) & $1476.48(1843.46)$ & $478.18(579.73)$ & $p<0.0001$ \\
\hline ARI initial dosage & Mean (SD) & - & $10.31(5.15)$ & NA \\
\hline ARI final dosage & Mean (SD) & - & $19.67(7.30)$ & NA \\
\hline \multirow[t]{2}{*}{ Any AE } & No & $51(25.76 \%)$ & $116(58.29 \%)$ & \multirow[t]{2}{*}{$p<0.0001$} \\
\hline & Yes & $147(74.24 \%)$ & $83(41.71 \%)$ & \\
\hline \multirow[t]{3}{*}{$\mathrm{AE}$} & Weight gain & $90(45.45 \%)$ & $10(5.03 \%)$ & $p<0.0001$ \\
\hline & Dizziness & $13(6.57 \%)$ & $10(5.03 \%)$ & $p=0.52$ \\
\hline & Appetite change & $20(10.10 \%)$ & $10(5.03 \%)$ & $P=0.06$ \\
\hline
\end{tabular}


Citation: $\quad$ Millier A, Briquet B, Georges N, Murthy V, Toumi M (2014) Reasons for Aripiprazole Discontinuation in Schizophrenia - A Retrospective Review. J Neurol Neurophysiol 5: 226. doi:10.4172/2155-9562.1000226

Page 5 of 8

\begin{tabular}{|c|c|c|c|c|}
\hline & Fatigue & $46(23.23 \%)$ & $10(5.03 \%)$ & $p<0.0001$ \\
\hline & GI Disturb & $2(1.01 \%)$ & $7(3.52 \%)$ & $p=0.17$ \\
\hline & Akathisia & $33(16.67 \%)$ & $51(25.63 \%)$ & $p=0.03$ \\
\hline & Sedation & $51(25.76 \%)$ & $11(5.53 \%)$ & $p<0.0001$ \\
\hline & Cognitive & $34(17.17 \%)$ & $1(0.50 \%)$ & $p<0.0001$ \\
\hline & Movement & $32(16.16 \%)$ & $7(3.52 \%)$ & $\mathrm{p}<0.0001$ \\
\hline & White blood disorder & $1(0.51 \%)$ & 0 & $p=1.00$ \\
\hline & Libido loss & $40(20.20 \%)$ & $3(1.51 \%)$ & $p<0.0001$ \\
\hline & Vision disturbance & $4(2.02 \%)$ & $3(1.51 \%)$ & $p=1.00$ \\
\hline & Vision changes & 0 & 0 & $p=1.00$ \\
\hline & Other & $11(5.56 \%)$ & $15(7.54 \%)$ & $p=0.42$ \\
\hline Any diabetes or cardiovascular & No & $186(93.94 \%)$ & $189(94.97 \%)$ & $p=0.66$ \\
\hline & Yes & $12(6.06 \%)$ & $10(5.03 \%)$ & \\
\hline Diabetes or cardiovascular event & $\begin{array}{l}\text { Stroke / Transient Ischemic } \\
\text { Attack }\end{array}$ & 0 & 0 & NA \\
\hline & $\begin{array}{l}\text { EKG changes cardiac rhythm } \\
\text { disturbance }\end{array}$ & $1(0.51 \%)$ & $1(0.50 \%)$ & NA \\
\hline & $\begin{array}{l}\text { Hypertension or blood } \\
\text { pressure change }\end{array}$ & $7(3.54 \%)$ & $4(2.01 \%)$ & $p=0.36$ \\
\hline & Chest pain & 0 & $1(0.50 \%)$ & $p=1.00$ \\
\hline & Diabetes / hyperglycemia & $7(3.54 \%)$ & $7(3.52 \%)$ & $p=1.00$ \\
\hline
\end{tabular}

Table 2: Antipsychotic treatment characteristics

Of patients who were prescribed aripiprazole, 5.9\% were prescribed another antipsychotic (2.4\% a SGA, and $3.5 \%$ a FGA). Antipsychotic treatments used before aripiprazole were used for about 4 years, on average, while aripiprazole was used for 1.7 years.

Dosage of aripiprazole increased over time; the average initial daily dosage was at about $10.52 \mathrm{mg}$, whereas the final dosage was at about twice this quantity $(19.51 \mathrm{mg})$.

Once aripiprazole was discontinued, most often prescribed antipsychotics after aripiprazole were risperidone (27\%), quetiapine (26\%) and olanzapine (17\%).

\section{Adverse events during antipsychotic treatment}

Before the use of aripiprazole, $74 \%$ of patients experienced adverse events. This proportion was significantly lower during aripiprazole treatment, at about $42 \%(\mathrm{p}<0.0001)$. Weight gain was the most prevalent adverse event occurring during the treatment used before aripiprazole $(45 \%)$. Sedation $(26 \%)$, fatigue $(23 \%)$, libido loss $(20 \%)$, cognitive (17\%) and movement disorders (16\%) were the other most common adverse events. During aripiprazole treatment, only $6 \%$ of the patients suffered weight gain; the only adverse event commonly occurring was akathisia, affecting $26 \%$ of patients, whereas before aripiprazole therapy this condition affected only $17 \%$ of patients. These results were generally consistent across the countries.

\section{Reason for antipsychotic treatment discontinuation}

Reasons for discontinuation of antipsychotics taken before aripiprazole and for aripiprazole are described in Figure 1. 


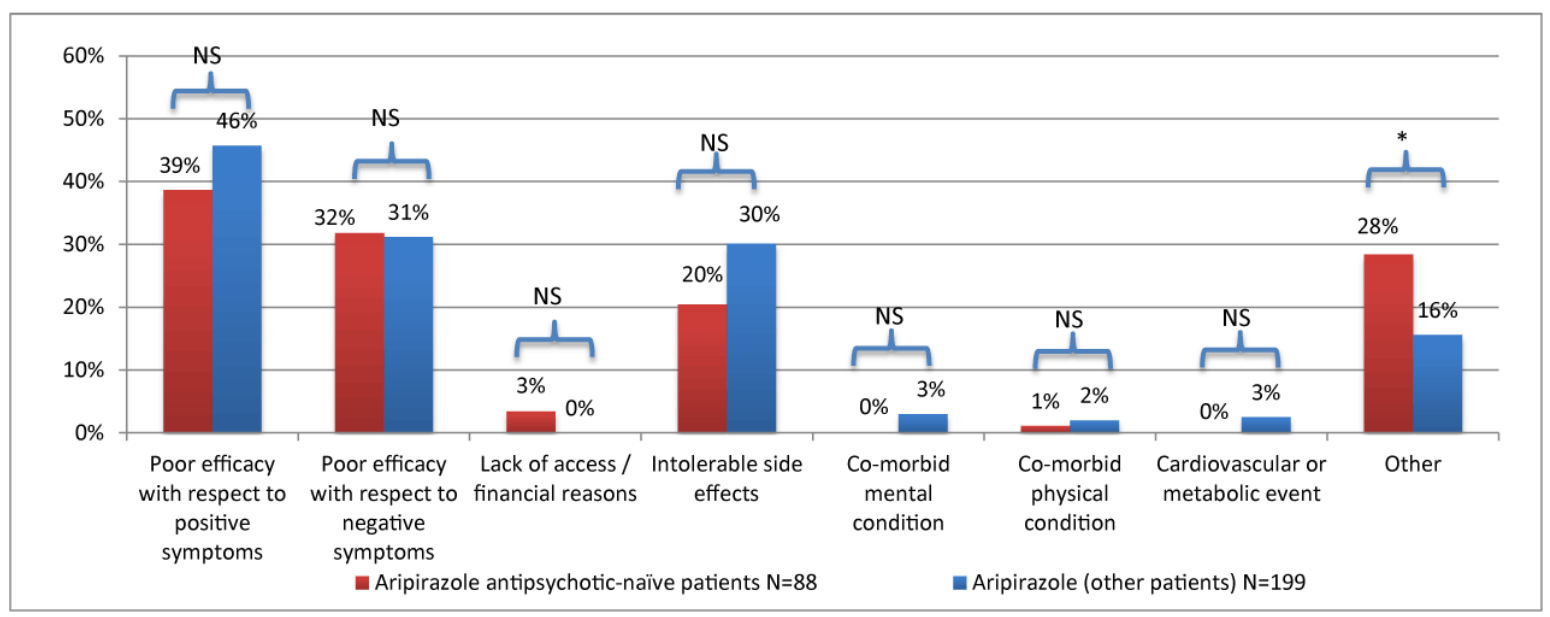

Footnote:

NS Not Significant, ${ }^{* * *} p<0.0001,{ }^{* *} p<0.01,{ }^{*} p<0.05$

Figure 1: Reasons for discontinuation

The most prevalent reasons for discontinuation of the antipsychotic treatment used before aripiprazole were the intolerable side effects (52\%), poor efficacy against negative symptoms (25.3\%) and poor efficacy against positive symptoms (39.9\%) (more than one reason could have been reported by the psychiatrist.) Other conditions accounted for $12.1 \%$ of the reasons for discontinuation of agents prior to the use of aripiprazole. Reasons were similar across the three countries surveyed.

Reasons for discontinuation of aripiprazole were primarily poor efficacy with respect to positive symptoms (43.6\%), poor efficacy with respect to negative symptoms (31.4\%), and intolerable side effects
(27.2\%). Again, reasons were similar across the three countries surveyed.

The most prevalent reasons for discontinuation were respectively for antipsychotics-naïve patients and other patients: poor efficacy against positive symptoms (38.6\% and $45.7 \%)$, poor efficacy against negative symptoms $(31.8 \%$ and $31.2 \%)$, intolerable side effects $(20.5 \%$ and $31.2 \%)$. No significant difference was found. Nevertheless, the rate of discontinuation due to other reason was significantly higher for anti-psychotic naïve patients $(28.4 \%$ vs. $15.6 \%, \mathrm{p}<0.05)$. This is shown in Figure 2.

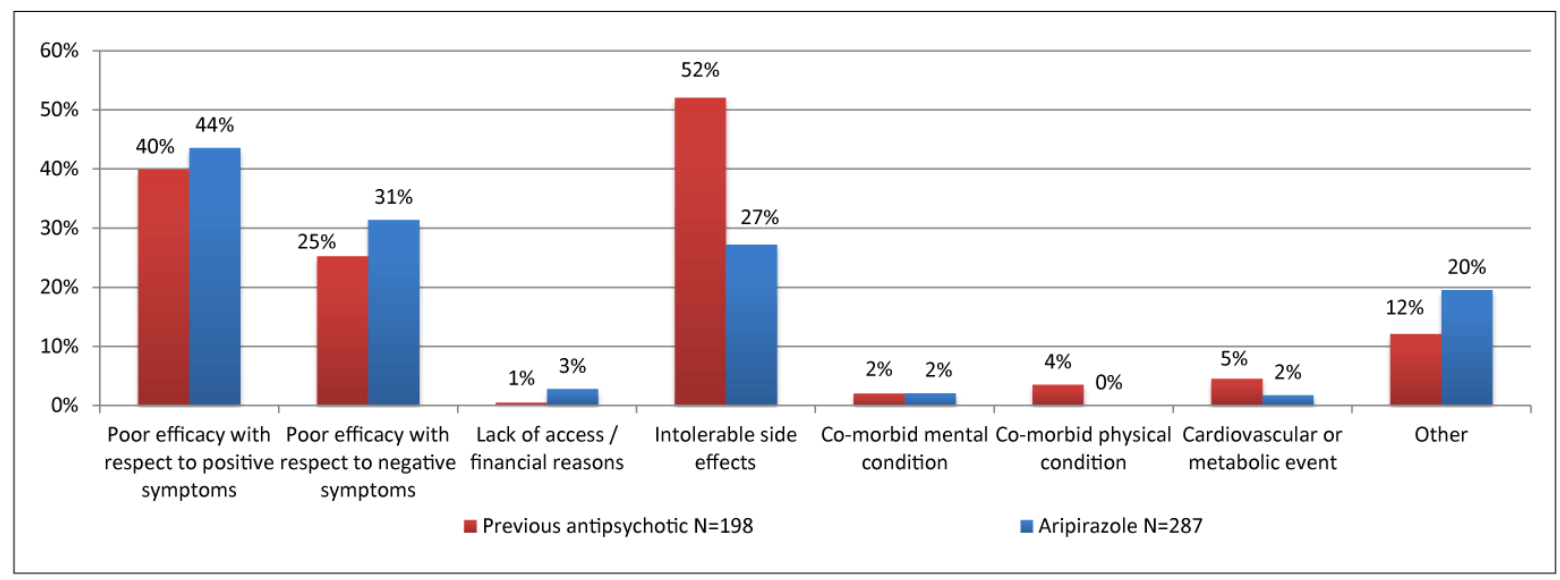

Figure 2: Reasons for discontinuation for patients under aripiprazole; NS Not Significant, ${ }^{\star * \star} \mathrm{p}<0.0001,{ }^{\star *} \mathrm{p}<0.01,{ }^{\star} \mathrm{p}<0.05$

Several clear associations between patient characteristics at initiation of aripiprazole and reasons for aripiprazole discontinuation were found (data not shown). Demographics characteristics did not differ in terms of gender or age, nevertheless patients stopping treatment with aripiprazole because of negative symptoms or intolerable side effects were more likely to live alone $(\mathrm{p}=0.01)$. Patients belonging to paranoid type were found to be more likely to stop aripiprazole treatment because of lack of efficacy on positive symptoms than other patients $(\mathrm{p}=0.03)$. Patients with a co-morbid mental condition (depression, insomnia, anxiety, insomnia, and 
others) were more likely to stop aripiprazole because of intolerable side effects $(\mathrm{p}=0.03)$, and patients with a physical condition, such as hypertension or diabetes, were more likely to stop aripiprazole because of lack of efficacy on positive symptoms $(\mathrm{p}=0.06)$. Although the type of therapy (monotherapy or polypharmacy) did not differ between reasons, patients under SGA were more likely to stop aripiprazole because of lack of efficacy on positive symptoms $(\mathrm{p}=0.38)$ and patients under FGA were more likely to stop because lack of efficacy on negative symptoms $(\mathrm{p}=0.04)$.

\section{Concomitant medication}

For each concomitant medication reported by the psychiatrist, the Anatomical Therapeutic Chemical (ATC) classification system was used to classify indications. All indications for concomitant medications, based on the ATC code (4th level), are described. The most often prescribed concomitant medications included hypnotics and sedatives ( $7 \%$ in France, $2 \%$ in Germany and 21\% in Sweden), anxiolytics (17\% in France, $8 \%$ in Germany and $12 \%$ in Sweden) and antidepressants (6\% in France, $4 \%$ in Germany and 5\% in Sweden). Rates for other medication (anticholinergic agents, antiepileptics, antihistamines, beta blocking agents, blood glucose lowering drugs or lipid modifying agents) were all below $3 \%$.

\section{Discussion}

In our study, information on why patients with schizophrenia started their antipsychotic treatment on aripiprazole, and why they decide to discontinue it/switch to another antipsychotic treatment was obtained through a web survey targeting psychiatrists in France, Germany and Sweden. Germany and France are the two biggest markets in Europe for aripiprazole, and Sweden was considered to fairly represent the Nordic countries. The sample of psychiatrists was found to be representative.

The demographic profile of patients included in this survey was consistent with published literature [13]. The distribution of schizophrenia by type of schizophrenia was also representative, with paranoid schizophrenia the predominant diagnosis [13,14]. The dosage of aripiprazole increased over time: the average initial dosage was at about $10.52 \mathrm{mg}$, whereas the final dosage was about twice this quantity $(19.51 \mathrm{mg})$, more in line with literature $[15,16]$.

As anticipated, the percentage of patients experiencing at least one adverse event was higher with other antipsychotics than with aripiprazole. For example, weight gain was found to be the most prevalent adverse event experienced with antipsychotic treatment used before aripiprazole (74\%); this was considerably higher than the rate seen with aripiprazole (42\%). The published literature about adverse events under aripiprazole treatment was recently found to be low [12], and it was difficult to compare this result to findings in clinical practice.

Surprisingly, length of antipsychotic treatment was much longer for the antipsychotics used before aripiprazole (4 years) than for aripiprazole (1.7 years). This suggests that psychiatrists may be more comfortable with other antipsychotic treatments, and/or that patients better tolerated other antipsychotic treatments, despite the safety profile of aripiprazole with regards to metabolic adverse events.

It is noteworthy that the most frequent reasons for aripiprazole treatment discontinuation and for discontinuation of the antipsychotic treatment received before aripiprazole differed: more patients stopped treatment with aripiprazole because of poor efficacy with respect to positive symptoms and fewer because of intolerable side effects. This are in line with results of previous published studies. A recent study aimed at identifying the reasons leading physicians to decide to switch antipsychotic treatment in outpatients with schizophrenia [17]. Using data from an observational 18-week including 574 patients, authors found that the main reason for switching antipsychotic treatment was lack of tolerability (65.0\%), followed by lack of efficacy (43.8\%). This supports our findings.

This study has several limitations. First, patients may have received some or part of their treatment in hospitals separate from the psychiatrist site, and the available data may not be as detailed as that from the hospital. However, psychiatrists are expected to ask and report this information in patient medical records. Second, the number of psychiatrists and patients included in the study is small. Although multivariate statistical analyses lacked power when investigated, descriptive results illustrated strong trends, and the results are thought to be generalizable overall. A larger study would allow further statistical analysis and further qualitative exploration of the reasons why patients with schizophrenia stop aripiprazole treatment.

\section{Conclusion}

This retrospective online survey of psychiatrists who treat patients with schizophrenia shows that aripiprazole seems to be prescribed mainly after intolerable side effects are observed with other therapies. The main reasons for aripiprazole discontinuation are lack of efficacy and, secondarily, intolerable side effects. The lack of alternatives with a reduced propensity for metabolic adverse events, especially weight gain, highlights a significant unmet need.

\section{Acknowledgement}

This article was funded by Takeda Pharmaceuticals. Nadia CadiSoussi and Venkatesha Murthy are employees of Takeda Pharmaceuticals. AurélieMillier and Benjamin Briquet are employees from Creativ-Ceutical which received funding from Takeda Pharmaceuticals. The authors have no other relevant affiliations or financial involvement with any organization or entity with a financial interest in or financial conflict with the subject matter or materials discussed in the manuscript. No writing assistance was utilized in the production of this manuscript.

\section{References}

1. van Os J, Kapur S (2009) Schizophrenia. See comment in PubMed Commons below Lancet 374: 635-645.

2. http://www.psychiatry.org/schizophrenia

3. Marwaha S, Johnson S (2004) Schizophrenia and employment - a review. See comment in PubMed Commons below Soc Psychiatry PsychiatrEpidemiol 39: 337-349.

4. Bushe CJ, Taylor M, Haukka J (2010) Mortality in schizophrenia: a measurable clinical endpoint. See comment in PubMed Commons below J Psychopharmacol 24: 17-25.

5. Kane JM, Correll CU (2010) Past and present progress in the pharmacologic treatment of schizophrenia. See comment in PubMed Commons below J Clin Psychiatry 71: 1115-1124.

6. Meyer JM (2001) Novel antipsychotics and severe hyperlipidemia. See comment in PubMed Commons below J ClinPsychopharmacol 21: 369-374. 
Citation: $\quad$ Millier A, Briquet B, Georges N, Murthy V, Toumi M (2014) Reasons for Aripiprazole Discontinuation in Schizophrenia - A Retrospective Review. J Neurol Neurophysiol 5: 226. doi:10.4172/2155-9562.1000226

Page 8 of 8

7. Yogaratnam J, Biswas N, Vadivel R, Jacob R (2013) Metabolic complications of schizophrenia and antipsychotic medications--an updated review. See comment in PubMed Commons below East Asian Arch Psychiatry 23: 21-28.

8. http://www.accessdata.fda.gov/drugsatfda_docs/label/ 2002/21436_Abilify_lbl.pdf

9. ema.europa.eu/Findmedicine/Human medicines/European public assessment reports

10. El-Sayeh HG, Morganti C, Adams CE (2006) Aripiprazole for schizophrenia. Systematic review. See comment in PubMed Commons below Br J Psychiatry 189: 102-108.

11. Croxtall JD (2012) Aripiprazole: a review of its use in the management of schizophrenia in adults. See comment in PubMed Commons below CNS Drugs 26: 155-183.

12. Leucht S, Pitschel-Walz G, Abraham D, Kissling W. Efficacy and extrapyramidal side-effects of the new antipsychotics olanzapine, quetiapine, risperidone, and sertindole compared to conventiona antipsychotics and placebo. A meta-analysis of randomized controlled trials. Schizophr Res 35: 51-68.

13. Bebbington PE, Angermeyer M, Azorin JM, Brugha T, Kilian R, et al. (2005) EuroSC Research Group. The European Schizophrenia Cohort
(EuroSC): a naturalistic prognostic and economic study. Soc Psychiatry PsychiatrEpidemiol 40: 707-717.

14. Gómez JC, Sacristán JA, Hernández J, Breier A, Ruiz Carrasco P, et al. (2000) The safety of olanzapine compared with other antipsychotic drugs: results of an observational prospective study in patients with schizophrenia (EFESO Study). Pharmacoepidemiologic Study of Olanzapine in Schizophrenia. See comment in PubMed Commons below J Clin Psychiatry 61: 335-343.

15. Citrome L, Reist C, Palmer L, Montejano L, Lenhart G, et al. (2009) Dose trends for second-generation antipsychotic treatment of schizophrenia and bipolar disorder. See comment in PubMed Commons below Schizophr Res 108: 238-244.

16. Coley KC, Fabian TJ, Kim E, Ammerman DK, Scipio TM, et al. (2008) Predictors of aripiprazole treatment continuation in hospitalized patients. See comment in PubMed Commons below J Clin Psychiatry 69: 1393-1397.

17. Roussidis A, Kalkavoura C, Dimelis D, Theodorou A, Ioannidou I, et al. (2013) Reasons and clinical outcomes of antipsychotic treatment switch in outpatients with schizophrenia in real-life clinical settings: the ETOS observational study. See comment in PubMed Commons below Ann Gen Psychiatry 12: 42. 